\title{
Degradation of Blue KN-R Dye in Batik Effluent by an Advanced Oxidation Process Using a Combination of Ozonation and Hydrodynamic Cavitation
}

\author{
Eva Fathul Karamah ${ }^{*}$ and Pristi Amalia Nurcahyani \\ Department of Chemical Engineering, Universitas Indonesia, Kampus UI, Depok 16424, Indonesia
}

*Corresponding author:

tel: $+62-81284363908$

email:eva@che.ui.ac.id

Received: July 18, 2017

Accepted: April 13, 2018

DOI: $10.22146 /$ ijc. 26733

\begin{abstract}
The popularity of batik has been increasing since it was declared as a world cultural heritage by UNESCO in 2009. Correspondingly, the content of textile dyes in textile industry wastewater is also increased. These dyes contain functional groups which make them quite stable in the environment and causes pollution. In this work, degradation of 100 ppm Blue KN-R has been investigated using ozonation, hydrodynamic cavitation, and a combination of the two for $60 \mathrm{~min}$. The three configuration methods were optimized in terms of different operating parameters, namely flowrate, initial $p H$ and dosage of ozone, to obtain the maximum degradation of Blue KN-R. It was found that the highest decolorization level for a single method was $70.16 \%$ for the single ozonation process at $\mathrm{pH} 11$ and $156.48 \mathrm{mg} / \mathrm{h}$ of ozone and $1.79 \%$ for the single hydrodynamic cavitation process at $\mathrm{pH}$ 4. The highest decolorization level was $79.39 \%$, achieved by the combination at $\mathrm{pH} 11$ and $156.48 \mathrm{mg} / \mathrm{h}$ of ozone. The mineralization level in the form of a percentage of Total Organic Carbon (TOC) removal by ozonation, hydrodynamic cavitation, and their combination was 14.81, 1.85, and 19.9\%, respectively. Due to its better performance, degradation of Blue KN-R was conducted by the hybrid method for $120 \mathrm{~min}$, resulting in $92.63 \%$ of decolorization and $24.54 \%$ of TOC removal. The degree of synergetic decolorization and mineralization was due to the mechanical and chemical effect of hydrodynamic cavitation in increasing ozone solubility and production of hydroxyl radicals. Degradation of batik effluent has been investigated in optimum conditions for $120 \mathrm{~min}$. The color, COD, BOD, and TSS removal were 67.96, $68.72,66.54$, and $79.84 \%$, respectively.
\end{abstract}

Keywords: Blue KN-R; decolorization; dye; hydrodynamic cavitation; ozonation

\section{- INTRODUCTION}

The textile industry is one of the industries that makes a significant contribution to Indonesia, and synthetic dyes are one of the raw materials in the industry, such as the batik industry. Textile dyes contain azo, anthraquinone, oxazine, phthalocyanine, and formazan functional groups such as the chromophore group [1]. Reactive dyes are widely used since the capacity of the reactive functional group makes it easy to bond with the hydroxyl functional group of the textile fibers to form covalent bonding. Thus, increasing interaction between the dye and the fibers occurs, as does decrease energy consumption [2]. Reactive Blue 19 is commonly used and is easily available [3]. Also known as Blue $\mathrm{KN}-\mathrm{R}$, it is a type of anthraquinone dye and is more difficult to decolorize than azo dyes because of its conjugated structure [4].

Advanced oxidation processes (AOPs) constitute a promising technology for the treatment of non-easily removable organic compounds. These processes are based on generating hydroxyl radicals $(\bullet \mathrm{OH})$, a powerful non-selective oxidizing agent that can react with various types of organic and inorganic compounds [5]. One of the AOP methods is ozonation. It is well known that ozone is a strong oxidant which can form a more powerful, non-selective hydroxyl radical at high $\mathrm{pH}$ values. However, ozone has some deficiencies, namely its solubility and stability in water is relatively low, and also the selectivity of ozone itself [6]. Ozone can be 
combined with hydrodynamic cavitation to increase its solubility and stability.

Cavitation is defined as the phenomenon of the formation, growth and subsequent collapse of microbubbles or cavities occurring in extremely small intervals of time (milliseconds), which release large amounts of energy [7]. In hydrodynamic cavitation, cavities are formed by passing the liquid through the constriction provided in flowline [8]. The extreme cavity condition can be used to attack the molecule bonds of organic pollutants [9]. Under such extreme conditions, water molecules are dissociated into $\bullet \mathrm{OH}$ and $\mathrm{H} \bullet$. These -OH then diffuse into the bulk liquid, where they react with organic pollutants and oxidize or mineralize them [10]. The combination of hydrodynamic cavitation and ozone can be used to intensify degradation efficiency due to the enhanced mass transfer of ozone molecules from the gas phase to the bulk solution, which reacts with organic pollutants in cavitating conditions [8]. Consequently, by combining ozonation and hydrodynamic cavitation, hydroxyl radical production will increase.

The purpose of this study is to investigate the degradation of Blue $\mathrm{KN}-\mathrm{R}$ using a combination of ozonation and hydrodynamic cavitation and compare it with corresponding singular methods in order to assess the significance of the combination. The effect of certain important variables, namely circulation flow rate, initial $\mathrm{pH}$ and dosage of ozone, were evaluated. The optimum operational condition was also used to treat batik effluent from Handayani Geulis Batik plant in Bogor.

\section{- EXPERIMENTAL SECTION}

\section{Materials}

The Blue KN-R dye molecule structure is shown in Fig. 1. (molecular weight: $626.55 \mathrm{~g} / \mathrm{mol}$; molecular formula: $\mathrm{C}_{22} \mathrm{H}_{16} \mathrm{~N}_{2} \mathrm{Na}_{2} \mathrm{O}_{11} \mathrm{~S}_{3}$ ). Ozone gas was generated using a commercial ozonator from HANACO. Sodium hydroxide ( $\mathrm{NaOH}$ p.a.) and sulphuric acid $\left(\mathrm{H}_{2} \mathrm{SO}_{4}\right.$ p.a.) from Merck were used to adjust the initial $\mathrm{pH}$ values, and potassium permanganate $\left(\mathrm{KMnO}_{4}\right.$ p.a.) from Merck was employed in the hydroxyl radical quantification. An indigo reagent (HACH Cat. 2518025) was used to determine

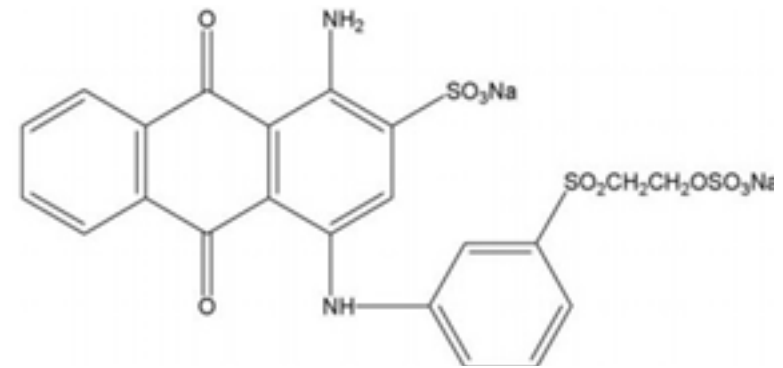

Fig 1. The molecular structure of Blue KN-R

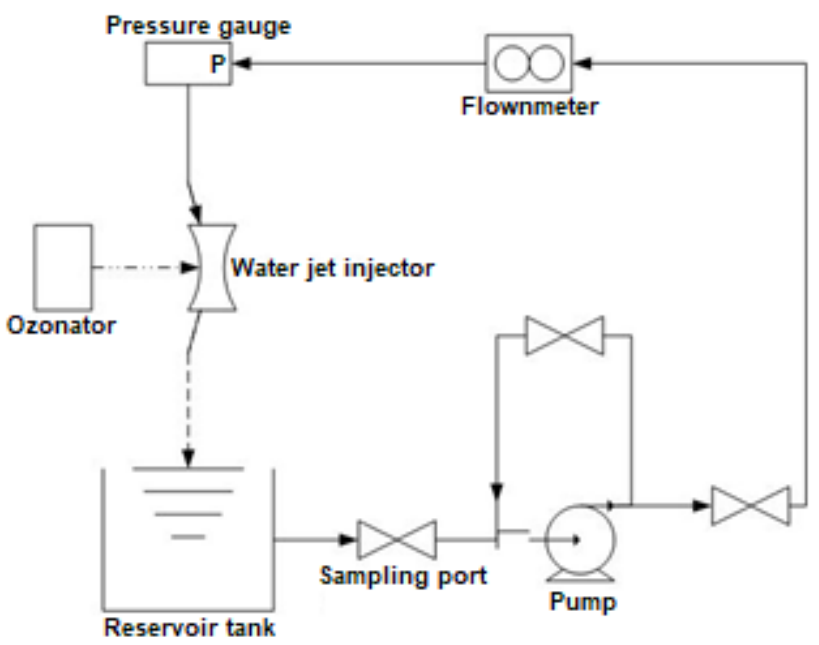

Fig 2. Schematic diagram of the experiment

the residual ozone concentration, and a COD reagent $(\mathrm{HACH}$ Cat. 2125925) to determine COD concentration.

\section{Instrumentation}

The experimental setup is shown in Fig. 2. It included a $6 \mathrm{~L}$ reservoir tank, a pump (power rating $370 \mathrm{~W}$ ), two control valves, flowmeter, pressure gauge, and injector (Venturi Mazzei type 384).

\section{Procedure}

\section{Quantification of hydroxyl radical}

Six Liters of aquademin was used for quantifying hydroxyl radical produced using three method configurations, single ozonation, single hydrodynamic cavitation, and a combination of the two, for $60 \mathrm{~min}$. The experiment using single hydrodynamic cavitation was conducted at various flow rates (2, 4, 6 LPM), while those using single ozonation and the combination were conducted at various initial $\mathrm{pH}$ values $(4,7,11)$ and ozone dosages (72, 120.96, $156.48 \mathrm{mg} / \mathrm{h}$ ). 


\section{Degradation of Blue $K N-R$}

Degradation of Blue KN-R was achieved using single ozonation, single hydrodynamic cavitation, and a combination of the two in various conditions, with a fixed aqueous Blue KN-R concentration of $100 \mathrm{mg} / \mathrm{L}$. All the experiments were conducted at various levels of initial $\mathrm{pH}$ $(4,7,11)$. Ozonation and the combined method were also conducted at various ozone dosages $(72,120.96,156.48$ $\mathrm{mg} / \mathrm{h}$ ). All the experiments were performed for $60 \mathrm{~min}$.

\section{Degradation of batik effluent}

The degradation of batik effluent (Handayani Geulis Batik in Bogor) was carried out in optimum conditions, and the experiment was performed for $120 \mathrm{~min}$. The degradation parameters of batik effluent were color scale using Platinum-Cobalt scale (Pt/Co) based on SNI 066989.80:2011 method; COD using a COD reagent and spectrophotometer for concentration analysis; $\mathrm{BOD}_{5}$ using SNI 6989.72:2009; and TSS using a colorimeter.

\section{- RESULTS AND DISCUSSION}

\section{Quantification of the Hydroxyl Radicals}

Hydroxyl radicals play an important role in the degradation of Blue KN-R dye because they are the main oxidizing agents that react with the original and intermediate compounds to achieve mineralization. The quantification of hydroxyl radicals for each of the configuration methods has therefore been investigated. For the hydrodynamic cavitation method, Fig. 3 shows that the number of hydroxyl radicals increased with an increase in flow rate; $6 \mathrm{LPM}$ of flow rate yielded $7.23 \mathrm{mg} / \mathrm{L}$ of hydroxyl radicals. Increasing the inlet velocity increases the pressure drop at the tubule, which causes the cavitation effect to be higher and leads to an increase in the level of hydroxyl radicals.

The results can be related to the cavitation number $\left(\mathrm{C}_{\mathrm{V}}\right)$, a dimensionless parameter that is used to characterize the cavitational intensity inside the cavitating device. It is defined as the ratio of pressure drop between the throat and extreme downstream section of the cavitating device (Fig. 4) to the kinetic head at the throat [11], and is given by Eq. 1:

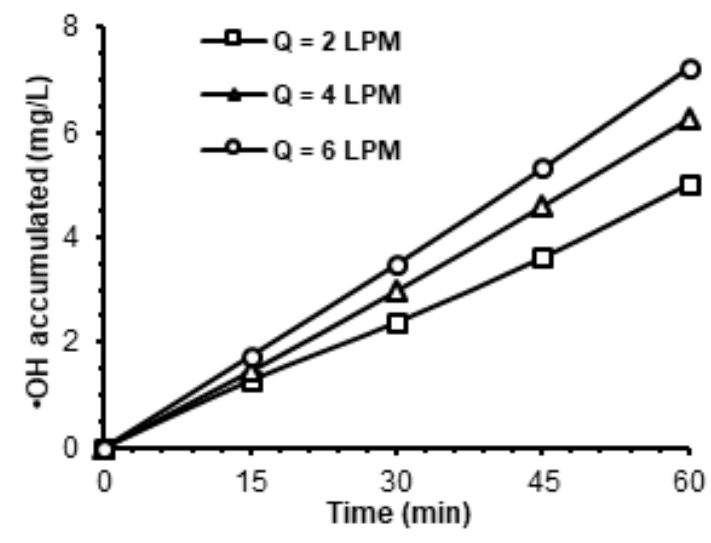

Fig 3. Effect of flow rate on hydroxyl radical production by hydrodynamic cavitation

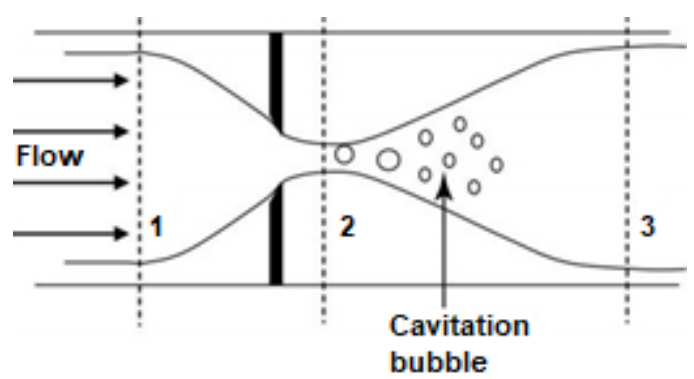

Fig 4. Pressure profile in the hydrodynamic cavitation where $\mathrm{P}_{2}$ is the fully recovered downstream pressure, $\mathrm{P}_{\mathrm{V}}$ is the vapor pressure of the liquid, $\mathrm{v}_{0}$ is the velocity at the throat of the cavitating device, and $\rho$ is the density of the liquid. As the inlet pressure increases, the velocity at the throat increases, which in turn reduces the cavitation number. In this experiment, the cavitation numbers at 2 , 4 , and 6 LPM were 8.67, 2.18, and 0.97, respectively. As the flow rate increases, the cavitation number decreases, which in turn generates more hydroxyl radicals

$C_{V}=\left(\frac{\mathrm{P}_{2}-\mathrm{P}_{\mathrm{V}}}{\frac{1}{2} \rho \mathrm{v}_{0}^{2}}\right)$

For the ozonation method, Fig. 5 shows that the level of hydroxyl radicals increased with the increase in initial $\mathrm{pH}$ value. This initial $\mathrm{pH}$ value $(4,7,11)$ yielded $6.12,7.27$, and $7.91 \mathrm{mg} / \mathrm{L}$ of hydroxyl radicals, respectively. In acidic conditions, ozone molecules will react directly and are not easily decomposed to hydroxyl radicals. However, in alkaline conditions ozone 


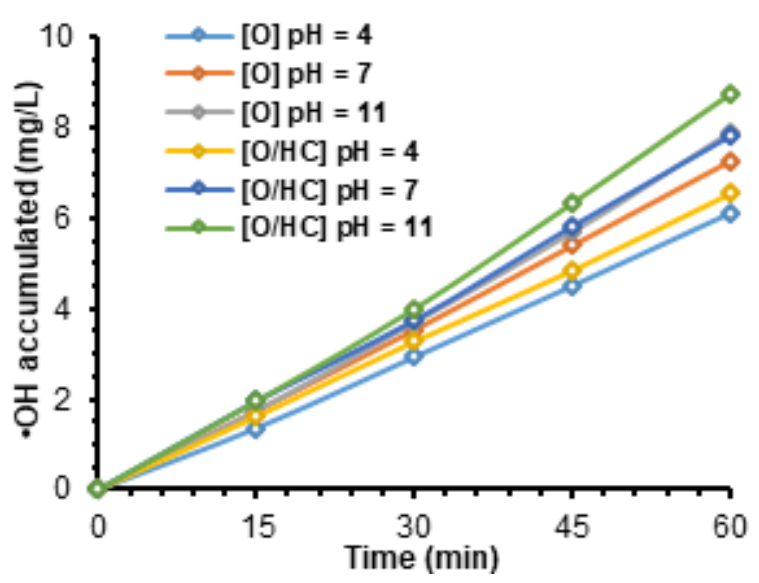

Fig 5. Effect of $\mathrm{pH}$ on hydroxyl radical production by ozonation $[\mathrm{O}]$ and the combination of ozonation and hydrodynamic cavitation $[\mathrm{O} / \mathrm{HC}]$

molecules will be decomposed to form hydroxyl radicals due to the presence of hydroxide ions. Fig. 6 shows that increasing the dosage of ozone will increase the level of hydroxyl radicals.

For the combination method, Fig. 6 shows the same trend as the ozonation method. The level of hydroxyl radicals at various initial $\mathrm{pH}(4,7,11)$ were $6.55,7.82$, $8.76 \mathrm{mg} / \mathrm{L}$, respectively, which was greater than in the ozonation method. Fig. 6 also shows a similar pattern to the ozonation method but is higher than single ozonation. The results indicate an increase in ozone mass transfer and the addition of hydroxyl radicals due to the mechanical and chemical effects of hydrodynamic cavitation.

\section{Degradation of Blue KN-R}

The degradation of Blue KN-R was conducted with various configuration methods and fixed dye concentration $(100 \mathrm{mg} / \mathrm{L})$ for $60 \mathrm{~min}$. Fig. 7 shows that in the ozonation method, the highest decolorization occurred under the alkaline condition $(\mathrm{pH} 11)$. In this condition, there are hydroxyl radicals which have higher oxidation potential than ozone molecules [12]. Fig. 8 shows that the decolorization is more effective if conducted at $156.48 \mathrm{mg} / \mathrm{h}$ of ozone. Increasing the dosage of ozone will increase the level of hydroxyl radicals from ozone decomposition, resulting in increasing decolorization of Blue KN-R.

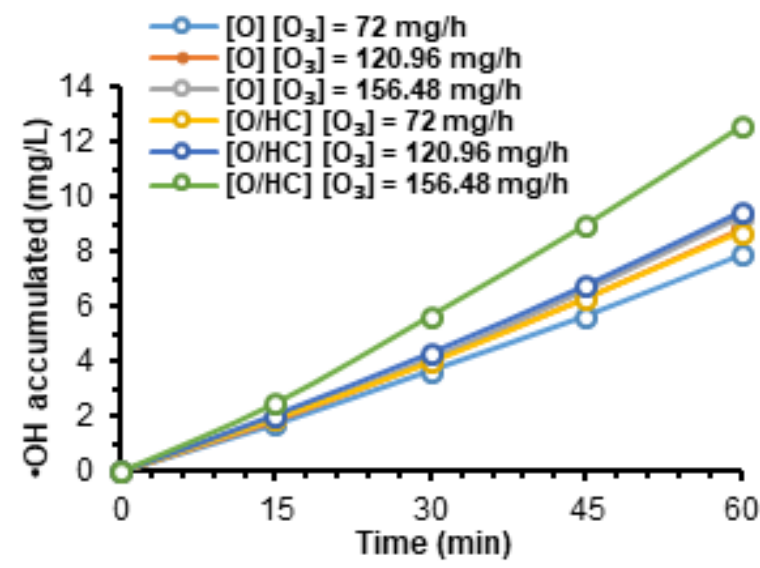

Fig 6. Effect of dosage of ozone on hydroxyl radical production by ozonation [O] and the combination of ozonation and hydrodynamic cavitation $[\mathrm{O} / \mathrm{HC}]$

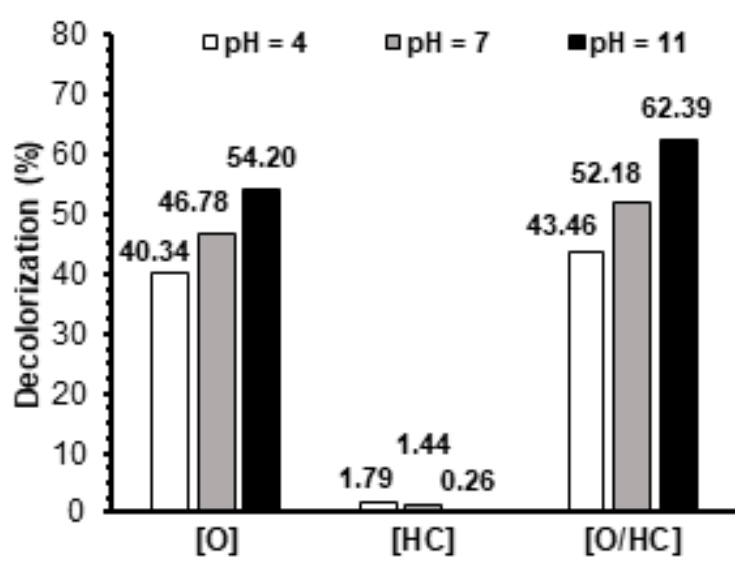

Fig 7. Effect of $\mathrm{pH}$ on Blue $\mathrm{KN}-\mathrm{R}$ decolorization by ozonation $[\mathrm{O}]$, hydrodynamic cavitation $[\mathrm{HC}]$, and their combination $[\mathrm{O} / \mathrm{HC}]$

For the hydrodynamic cavitation method, Fig. 7 shows that decolorization increases with the decreases in initial $\mathrm{pH}$. The increase in decolorization at a lower $\mathrm{pH}$ can be attributed to the fact that dye molecules are present in a molecular state at lower $\mathrm{pH}$ rather than in ionic state. In this molecular state, dye molecules become more hydrophobic, and hence can easily locate or prefer to be at the gas-water interface of the collapsing cavities [8].

The combination of ozonation and hydrodynamic cavitation can increase the efficiency of degradation due to the increase in the ozone mass transfer from the gas phase to the bulk solution and its reaction with 
organic pollutants in cavitating conditions. Moreover, under the cavitational effect, ozone is easily decomposed, yielding molecular $\mathrm{O}_{2}$ and atomic oxygen which reacts with a water molecule to form hydroxyl radicals. The following reactions (Eq. 2-7) can occur during the process of combined ozone and hydrodynamic cavitation [10-11].

$\mathrm{O}_{3} \stackrel{\mathrm{HC}}{\longrightarrow} \mathrm{O}_{2}+\mathrm{O}\left({ }^{3} \mathrm{P}\right)$

$\mathrm{H}_{2} \mathrm{O} \stackrel{\mathrm{HC}}{\longrightarrow} \cdot \mathrm{H}+\cdot \mathrm{OH}$

$\mathrm{O}\left({ }^{3} \mathrm{P}\right)+\mathrm{H}_{2} \mathrm{O} \rightarrow 2 \cdot \mathrm{OH}$

$\cdot \mathrm{OH}+\cdot \mathrm{OH} \rightarrow \mathrm{H}_{2} \mathrm{O}_{2}$

Blue $\mathrm{KN}-\mathrm{R}+\cdot \mathrm{OH} \rightarrow \mathrm{CO}_{2}+\mathrm{H}_{2} \mathrm{O}+$ degradation product

Blue $\mathrm{KN}-\mathrm{R}+\mathrm{O}_{3} \rightarrow \mathrm{CO}_{2}+\mathrm{H}_{2} \mathrm{O}+$ degradation product

For the combination method, the results shown in Fig. 7 have a similar pattern to the effect of $\mathrm{pH}$ in the ozonation method. The highest decolorization was observed at $\mathrm{pH} 11$, which is higher than the decolorization by single ozonation. Moreover, Fig. 8 shows that the highest decolorization by the combination method was observed at the highest dosage of ozone, which is greater than decolorization by single ozonation. Moreover, the difference in decolorization level between the three configuration methods shows a synergetic effect and indicates that the combination of ozonation and hydrodynamic cavitation can improve the degradation of Blue KN-R.

The optimum operational conditions were observed using a combination of ozonation and hydrodynamic cavitation at $\mathrm{pH} 11$ and $156.48 \mathrm{mg} / \mathrm{h}$ dosage of ozone. Consequently, the degradation of Blue $\mathrm{KN}-\mathrm{R}$ was investigated using optimum conditions for $120 \mathrm{~min}$, and decolorization reached $92.63 \%$ remaining $7.37 \mathrm{mg} / \mathrm{L}$ of dyes.

The ultimate goal of the oxidation process is mineralization, namely the conversion of organic compounds into simple inorganic compounds such as $\mathrm{CO}_{2}$ and $\mathrm{H}_{2} \mathrm{O}$. The number of organic compounds converted into minerals is expressed in Total Organic Carbon (TOC). Thus the TOC removal rate is also called the level of mineralization of an oxidation process. In order to study the mineralization rate, TOC was evaluated for the three configuration methods at $60 \mathrm{~min}$. The TOC removal for ozonation, hydrodynamic cavitation, and the combined method was 14.81, 1.85, and $19.9 \%$, respectively. Moreover, TOC removal in optimum conditions after 120 min was $24.54 \%$.

Shen et al. [13] investigated the degradation of reactive red X-3B dye by ultrasonic (US) cavitation and ozone oxidation. They reported that the $\mathrm{O}_{3} / \mathrm{US}$ cavitation system has synergetic degradation effect on reactive red X-3B dye compared with $\mathrm{O}_{3}$ alone or US cavitation alone. Under the condition that the initial concentration of $100 \mathrm{mg} / \mathrm{L}, \mathrm{pH}$ of 6.52 , ozone flux of 40 $\mathrm{L} / \mathrm{h}$, and $99.2 \%$ decolorization efficiency was obtained in $\mathrm{O}_{3} /$ US cavitation system.

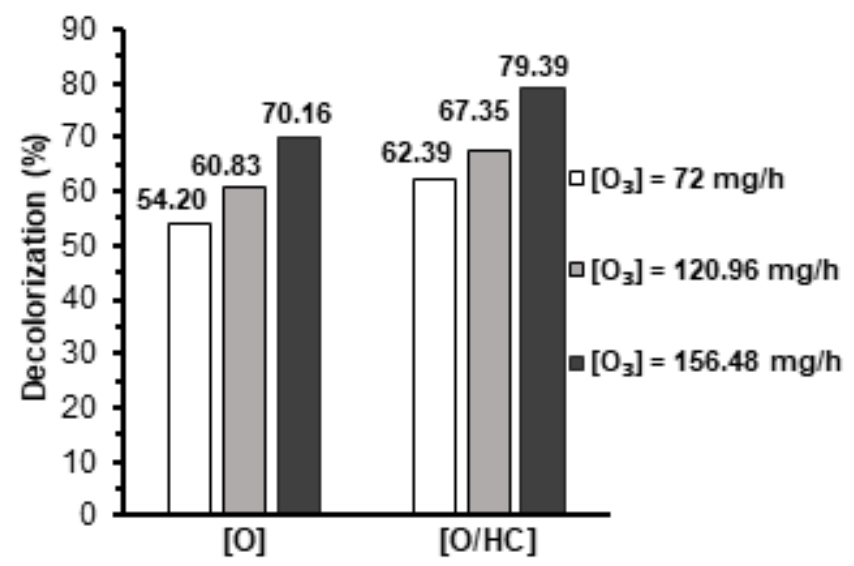

Fig 8. Effect of dosage of ozone on Blue KN-R decolorization by ozonation $[\mathrm{O}]$ and the combination of ozonation and hydrodynamic cavitation $[\mathrm{O} / \mathrm{HC}]$

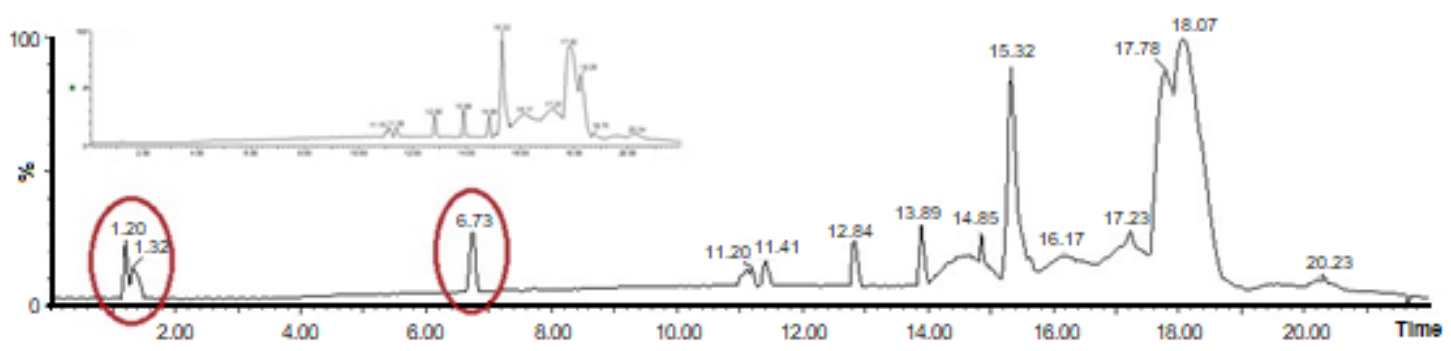

Fig 9. LC-MS chromatogram of mobile phase and sample of 120 min degradation process 
Table 1. Identification of degradation product by LC-MS

\begin{tabular}{lcclc}
\hline No. & Retention time $(\mathrm{min})$ & $\mathrm{m} / \mathrm{z}$ & Chemical formula & Area (\%) \\
\hline 1 & 1.20 & 125.9 & $\mathrm{C}_{2} \mathrm{~N}_{5} \mathrm{~S}$ & 25.05 \\
2 & 1.32 & 164.9 & $\mathrm{C}_{2} \mathrm{~N}_{2} \mathrm{OS}_{3}$ & 28.25 \\
3 & 6.73 & 183.0 & $\mathrm{C}_{8} \mathrm{H}_{9} \mathrm{NO}_{2} \mathrm{~S}$ & 41.37 \\
\hline
\end{tabular}

\section{Degradation Products}

In order to identify the degradation products of Blue $\mathrm{KN}-\mathrm{R}$, liquid chromatography-mass spectrometry (LCMS) analysis was performed on the sample from the optimum conditions at $120 \mathrm{~min}$. Based on the chromatogram, three peaks were detected in three retention times (Fig. 9). These peaks indicate three different compounds in the sample, as shown in Table 1.

\section{Degradation of Batik Effluent}

The degradation of batik effluent from Handayani Geulis Batik Bogor was evaluated using optimum operating conditions for $120 \mathrm{~min}$. The batik effluent was diluted to aquademin with a volume ratio of 1:5 (batik effluent:aquademin). The evaluation of the dye degradation consisted of two parameters, Blue KN-R concentration, and color (Pt-Co units). The decolorization of Blue KN-R was $66.66 \%$, with an initial concentration of $70.31 \mathrm{mg} / \mathrm{L}$. Color concentration in the initial conditions was $2422 \mathrm{Pt}$-Co units and after the degradation process fell to 744 Pt-Co units (69.28\%). The low level of degradation color in the batik effluent might be explained by the content of effluent being not only Blue KN-R but also other ingredients used in the dyeing process.

The initial COD concentration from batik effluent was $169.98 \mathrm{mg} / \mathrm{L}$, and after degradation for $120 \mathrm{~min}$, the COD removal yield was $68.72 \%(53.17 \mathrm{mg} / \mathrm{L})$. The low COD removal may be related to the presence of organic compounds that easily oxidize and partially oxidize [14]. BOD reduction reached $66.54 \%$ with an initial BOD concentration of $28 \mathrm{mg} / \mathrm{L}$. However, the BOD/COD ratio before and after the degradation process only increased from 0.16 to 0.18 (lower than 0.2 ). This result indicates the presence of non-biodegradable oxidation products.

The other parameter that was evaluated from the degradation of batik effluent was TSS (Total Suspended Solids). This proposed method was able to reduce TSS from 610 to $123 \mathrm{mg} / \mathrm{L}$ (79.84\%). This TSS reduction was caused by the reaction of ozone in the effluent, which formed flocks that absorbed the colloids [15]. Other than that, the oxidation process by ozone molecules or hydroxyl radicals caused the decomposition of large organic compounds to become smaller, so TSS concentration decreased [16]. Rajoriya et al. [17] investigated the treatment of textile dyeing industry effluent using hydrodynamic cavitation (HC) in combination with several advanced oxidation reagents such as air, oxygen, ozone and Fenton's reagent. They found that all combined processes exhibited higher TOC, COD and color removal as compared to that obtained by $\mathrm{HC}$ alone.

\section{- CONCLUSION}

Ozonation, hydrodynamic cavitation, and a combination of the two were evaluated for the degradation of Blue $\mathrm{KN}-\mathrm{R}$. It was found that the combined method gave the synergetic effect compared to the single methods. The higher the $\mathrm{pH}$ and the more ozone used, the better the decolorization achieved. The highest degradation was achieved in alkaline conditions and with the highest dosage of ozone. For a $120 \mathrm{~min}$ degradation process in optimum conditions, the decolorization level and TOC removal were 92.63 and $24.54 \%$, respectively. The result of the degradation of batik effluent was over $60 \%$ of degradation for each parameter. In addition, the hybrid method shows a higher mechanical and chemical effect from hydrodynamic cavitation, indicated by the increases in the ozone solubility, level of hydroxyl radicals and degree of degradation.

\section{- ACKNOWLEDGMENTS}

The authors would like to thank PITTA 2017 No. 775/UN2.R3.1/HKP.05.00/2017 from Universitas 
Indonesia for providing financial support for this research.

\section{- REFERENCES}

[1] Trivedi, K.N., Boricha, A.B., Bajaj, H.C., and Jasra, R.V., 2009, Adsorption of remazol brilliant blue $\mathrm{R}$ dye from water by polyaluminium chloride, Rasayan J. Chem., 2 (2), 379-385.

[2] Rezaee, A., Ghaneian, M.T., Hashemian, S.J., Moussavi, G., Khavanin, A., and Ghanizadeh, G., 2008, Decolorization of reactive blue 19 dye from textile wastewater by the $\mathrm{UV} / \mathrm{H}_{2} \mathrm{O}_{2}$ process, J. Appl. Sci., 8 (6), 1108-1112.

[3] McCallum, J.E.B., Madison, S.A., Alkan, S., Depinto, R.L., and Wahl, R.U.R., 2000, Analytical studies on the oxidative degradation of the reactive textile dye Uniblue A, Environ. Sci. Technol., 34 (24), 5157-5164.

[4] Dong, X.L., Zhou, J.T., and Liu, Y., 2003, Peptoneinduced biodecolorization of reactive brilliant blue (KN-R) by Rhodocyclys gelatinosus XL-1, Process Biochem., 39 (1), 89-94.

[5] da Silva, C.R., Maniero, M.G., Rath, S., and Guimaraes, J.R., 2011, Antibacterial activity inhibition after the degradation flumequine by $\mathrm{UV} / \mathrm{H}_{2} \mathrm{O}_{2}$, J. Adv. Oxid. Technol., 14 (1), 106-114.

[6] von Gunten, U., 2003, Ozonation of drinking water: Part I. Oxidation kinetics and product formation, Water Res., 37 (7), 1443-1467.

[7] Shah, Y.T., Pandit, A.B., and Moholkar, V.S., 1999, Cavitation Reaction Engineering, Kluwer Academic/Plenum Publisher, New York.

[8] Saharan, V.K., Badve, M.P., and Pandit, A.B., 2011, Degradation of reactive red 120 dye using hydrodynamic cavitation, Chem. Eng. J., 178, 100-107.

[9] Jyoti, K.K., and Pandit, A.B., 2003, Hybrid cavitation methods for water disinfection: Simultaneous use of chemical with cavitation, Ultrason. Sonochem., 10 (45), 255-264.
[10] Gore, M.M., Saharan, V.K., Pinjari, D.V., Chavan, P.V., and Pandit, A.B., 2013, Degradation of reactive orange 4 dye using hydrodynamic cavitation based hybrid techniques, Ultrason. Sonochem., 21 (3), 1075-1082.

[11] Rajoriya, S., Bargole, S., and Saharan, V.K., 2016, Degradation of a cationic dye (Rhodamine 6G) using hydrodynamic cavitation coupled with other oxidative agents: Reaction mechanism and pathway, Ultrason. Sonochem., 34, 183-194.

[12] Muthukumar, M., Sargunamani, D., Selvakumar, N., and Rao, J.V., 2004, Optimisation of ozone treatment for colour and COD removal of acid dye effluent using central composite design experiment, Dyes Pigm., 63 (2), 127-134.

[13] Shen, Y., Xu, Q., Wei, R., Ma. J., and Wang, Y., 2017, Mechanism and dynamic study of reactive red $\mathrm{X}$-3B dye degradation by ultrasonic-assisted ozone oxidation process, Ultrason. Sonochem., 38, 681692.

[14] Camel, V., and Bermond, A., 1998, The use of ozone and associated oxidation processes in drinking water treatment, Water Res., 32 (11), 3208-3222.

[15] Isyuniarto, A., 2009, Pengaruh waktu ozonasi terhadap penurunan kadar COD, BOD, TSS, dan fosfat pada limbah cair rumah sakit, Ganendra, 7 (1), 45-49.

[16] Suryana, M.D., 2016, Penyisihan sianida dan chemical oxygen demand dari limbah cair industri tepung tapioka dengan teknik ozonasi adsorpsi menggunakan granular activated carbon, Thesis, Department of Chemical Engineering, Faculty of Engineering, Universitas Indonesia, Depok.

[17] Rajoriya, S., Bargole, S., George, S., and Saharan, V.K., 2018, Treatment of textile dyeing industry effluent using hydrodynamic cavitation in combined with advanced oxidation reagents, $J$. Hazard. Mater., 344, 1109-1115. 